University of Nebraska - Lincoln

DigitalCommons@University of Nebraska - Lincoln

Roger Kirby Publications

Research Papers in Physics and Astronomy

4-15-1999

\title{
Enhancement of coercivity in nanometer-size CoPt crystallites
}

Sy_Hwang Liou

University of Nebraska-Lincoln, sliou@unl.edu

S. Huang

University of Nebraska-Lincoln

Elizabeth S. Klimek

University of Nebraska-Lincoln, eklimek@nmsu.edu

Roger D. Kirby

University of Nebraska-Lincoln, rkirby1@unl.edu

Follow this and additional works at: https://digitalcommons.unl.edu/physics_kirby

Part of the Physics Commons

Liou, Sy_Hwang; Huang, S.; Klimek, Elizabeth S.; and Kirby, Roger D., "Enhancement of coercivity in nanometer-size CoPt crystallites" (1999). Roger Kirby Publications. 7.

https://digitalcommons.unl.edu/physics_kirby/7

This Article is brought to you for free and open access by the Research Papers in Physics and Astronomy at DigitalCommons@University of Nebraska - Lincoln. It has been accepted for inclusion in Roger Kirby Publications by an authorized administrator of DigitalCommons@University of Nebraska - Lincoln. 


\title{
Enhancement of coercivity in nanometer-size CoPt crystallites
}

\author{
S. H. Liou, ${ }^{\text {a) }}$ S. Huang, E. Klimek, and R. D. Kirby \\ Department of Physics and Astronomy, Center for Materials Research and Analysis, \\ University of Nebraska, Lincoln, Nebraska 68588-0111 \\ Y. D. Yao \\ Institute of Physics, Academic Sinica, Taipei 115, Taiwan
}

In this study, we showed that a magnetic coercivity $\left(H_{c}\right)$ as high as $37 \mathrm{kOe}$ was obtained in a CoPt thin film that contains separated nanometer-size CoPt crystallites. We prepared CoPt thin films with thicknesses of 5 and $175 \mathrm{~nm}$ by magnetron sputtering. After annealing in an $\mathrm{Ar} / \mathrm{H}_{2}$ atmosphere at temperatures from 650 to $750{ }^{\circ} \mathrm{C}$ for $3-12 \mathrm{~h}$, we measured the magnetic properties and found that magnetic $H_{c}$ relates to annealing temperature, annealing time and film thickness. From atomic force microscopy and magnetic force microscopy studies, the magnetic single domain size of CoPt is in the range of $100-200 \mathrm{~nm}$. The high $H_{c}$ is likely due to the well-separated nanometer-size crystallites and the well-ordered fct phase of CoPt alloy. (c) 1999 American Institute of Physics. [S0021-8979(99)51108-0]

\section{INTRODUCTION}

Many magnetic devices are required to have high magnetic coercivity $\left(H_{c}\right)$, such as magnetic bias films of magneto-resistive elements, magnetic tips for magnetic force microscopy, high-density magnetic recording media, and magneto-optic recording media. ${ }^{1-7}$ The CoPt binary alloy is an excellent system because of its chemical stability and high magnetic anisotropy. The anisotropy of CoPt compounds is as high as $4 \times 10^{7} \mathrm{ergs} / \mathrm{cm}^{3}$ and the saturation magnetization is about $800 \mathrm{emu} / \mathrm{cm}^{3}$. From the calculation of StonerWohlfarth theory, $H_{c}=0.98 K / M_{s}$, where $K$ is the anisotropy constant and $M_{s}$ is the saturation magnetization. Thus, an $H_{c}$ around $49 \mathrm{kOe}$ is expected. ${ }^{8,9}$

It has been shown that the ordered fct structure can be obtained in the temperature range of $600-850{ }^{\circ} \mathrm{C}$. The transmission electron microscopy (TEM) result also established that $\mathrm{CoPt}$ samples with ordered fct structure were achieved after being annealed at $750{ }^{\circ} \mathrm{C}$ for $30 \mathrm{~min}^{5}$

As shown in the previous article, the high coercivity value of about $30 \mathrm{kOe}$ was observed in a CoPt film with nanometer-size crystallites. For this article, we directly measured the magnetic domain structure using magnetic force microscopy (MFM). We also show that a CoPt film with a much higher coercivity value was prepared by a two-step annealing process.

\section{EXPERIMENT}

The CoPt alloy films were prepared on fused quartz substrates by direct current magnetron sputtering. The target was made by mixing high-purity $\mathrm{Co}$ and $\mathrm{Pt}$ powder with a 1:1 atomic ratio and sintered at $1050{ }^{\circ} \mathrm{C}$ for $24 \mathrm{~h}$. The base pressure before introducing the Ar gas was $2 \times 10^{-8}$ Torr. The chamber pressure during sputtering was $10^{-2}$ Torr. The film thickness was in the range of 5-175 $\mathrm{nm}$. To improve the ordering and to control the separation of crystallites, the

\footnotetext{
${ }^{\text {a)} E l e c t r o n i c ~ m a i l: ~ s l i o u @ u n l i n f o . u n l . e d u ~}$
}

CoPt films were annealed under an $\mathrm{Ar} / \mathrm{H}_{2}$ atmosphere in the temperature range of $650-750{ }^{\circ} \mathrm{C}$, and the range of annealing time was from 3 to $12 \mathrm{~h}$. The magnetic properties of the films were measured by a superconducting quanturn interference device magnetometer. The morphology and the magnetic domain structure of the CoPt films were examined by atomic force microscopy (AFM) and MFM.

\section{RESULTS AND DISCUSSIONS}

The observed high $H_{c}$ in the CoPt film can be explained by the presence of the well ordered nanometer-size crystallites. These crystallites are noninteracting and form a random single-domain system. ${ }^{5}$ However, there is no direct evidence from early studies. In this article, we present the direct measurements of the magnetic domain structure of these high $H_{c}$ CoPt films from MFM and the comparison of the magnetic properties of the CoPt films with different annealing conditions.

Hysteresis loops of CoPt films with different thicknesses on quartz substrates, measured at $300 \mathrm{~K}$, are shown in Fig. 1 . Both of the samples were annealed at $750{ }^{\circ} \mathrm{C}$ for $3 \mathrm{~h}$. Figure 1(a) is the sample with the thickness of $175 \mathrm{~nm}$. An $H_{c}$ of 12 $\mathrm{kOe}$ and a saturation magnetization of $734 \mathrm{emu} / \mathrm{cm}^{3}$ were observed. Figure 1(b) is the sample with the thickness of 5 $\mathrm{nm}$. An $H_{c}$ of $16 \mathrm{kOe}$ and a saturation magnetization of 680 $\mathrm{emu} / \mathrm{cm}^{3}$ were observed. The small variation of the saturation magnetization may be due to the difficulty in the thickness measurement for the 5-nm-thick film. The major difference between these two films is their $H_{c}$ values. We observed some variation of $H_{c}$ values from samples that were not prepared in the same sputtering run. However, the $H_{c}$ value of the 175 -nm-thick film was always much less than that of the 5-nm-thick film when they were annealed in the same conditions.

Figures 2 and 3 are the AFM and MFM images of the same films (annealed at $750{ }^{\circ} \mathrm{C}$ for $3 \mathrm{~h}$, with thicknesses of 5 and $175 \mathrm{~nm}$. As shown in Fig. 2(a), the 5-nm-thick film contains well-separated nanometer-size crystallites as indi- 

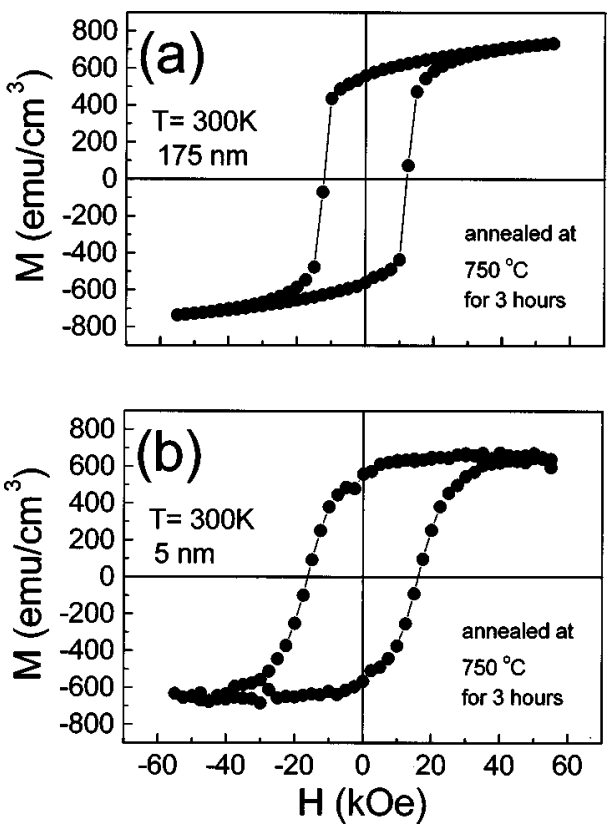

FIG. 1. Hysteresis loops of CoPt films on quartz substrates and annealed at $750{ }^{\circ} \mathrm{C}$ for $3 \mathrm{~h}$ and measured at $300 \mathrm{~K}$. The film thicknesses are (a) 175 and (b) $5 \mathrm{~nm}$.

cated in the AFM image. The sizes of the crystallites are in the range of 100-400 $\mathrm{nm}$. The height of crystallites is in the range of $20-80 \mathrm{~nm}$. The MFM image, Fig. 2(b), was obtained using a CoPt MFM tip magnetized parallel to the sample surface. The light and dark contrast corresponds to the strength of the stray-field gradient on the sample surface. The lighter color represents a frequency shift in the MFM tip when the magnetization of the sample and that of the MFM tip are repulsive. As shown in Fig. 2(b), crystallites with one light and dark area are single-domain (as indicated by " $S$ "); the grain that may contain a few crystallites with two or more light and dark areas are multidomain (as indicated by " $M$ '). The size of a single-domain crystallite is between 100 and $200 \mathrm{~nm}$. Figure 3 shows the AFM and MFM images of

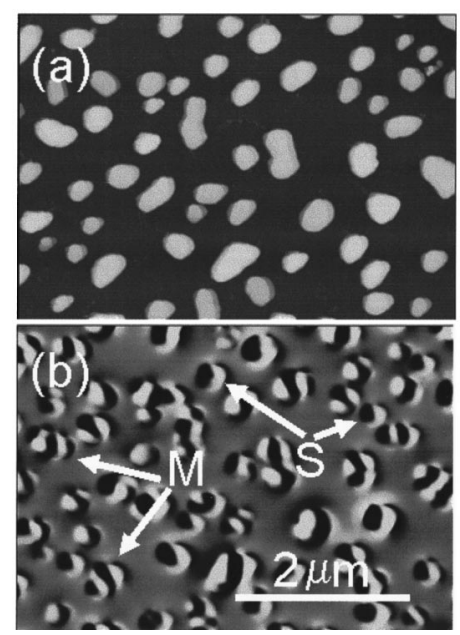

FIG. 2. The topographic (a) and magnetic (b) images of a 5-nm-thick CoPt film on a quartz substrate, annealed at $750{ }^{\circ} \mathrm{C}$ for $3 \mathrm{~h}$. $M$ indicates a multidomain grain. $S$ indicates a single-domain grain.
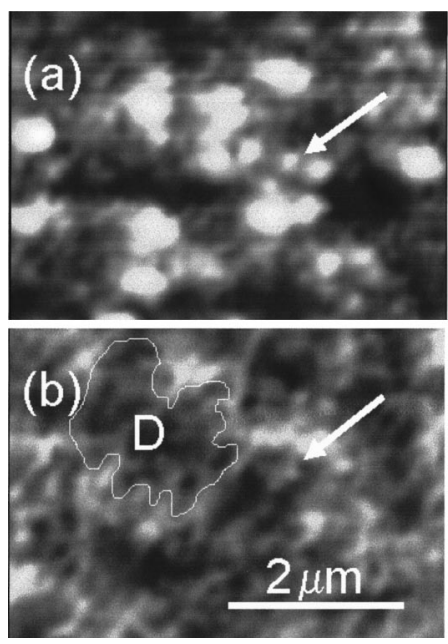

FIG. 3. The topographic (a) and magnetic (b) images of a 175-nm-thick CoPt film on a quartz substrate, annealed at $750{ }^{\circ} \mathrm{C}$ for $3 \mathrm{~h}$. The arrows indicate the typical crystallite size and its corresponding magnetic domain. A region of coupled magnetic domains is marked by $D$.

the sample with the film thickness of $175 \mathrm{~nm}$. The roughness of the film surface is in the range of $50-100 \mathrm{~nm}$. The crystallites of the 175-nm-thick film are not separated. However, the size of the crystallites is in the range of $100-400 \mathrm{~nm}$, as indicated by the arrow in Fig. 3(a). This is also consistent with the results from the TEM study that was reported previously. ${ }^{5}$ As shown in Fig. 3(b), the magnetic domains of the crystallites with about the same direction are coupled together so that they form much larger white and dark area. The size of the magnetic domain, as indicated by an arrow in Fig. 3(b), is about a few hundred nanometers. The major difference between these two films is that the 5-nm-thick film contains many noninteracting nanometer-size magnetic domain and the 175-nm-thick film has more magnetic inter-
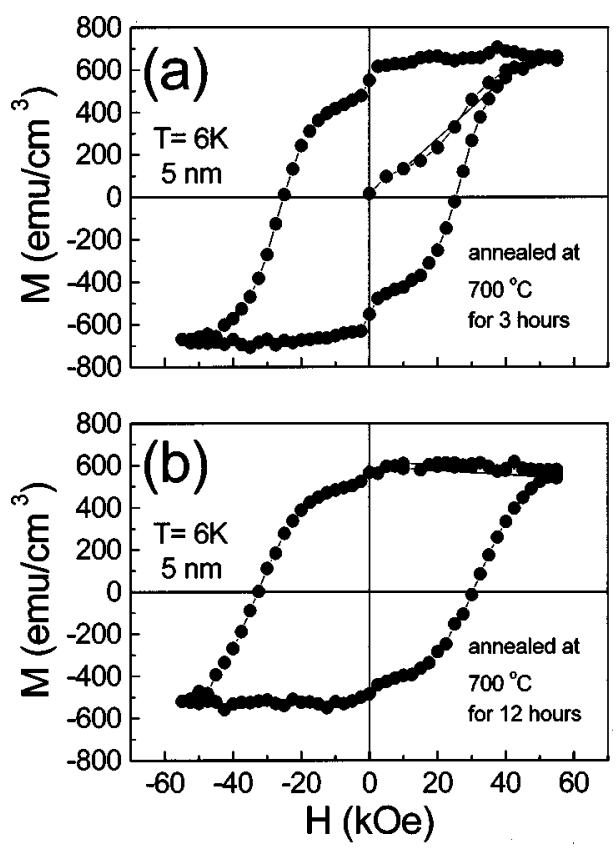

FIG. 4. Hysteresis loops of $5 \mathrm{~nm}$ CoPt films on quartz substrates, annealed for $3 \mathrm{~h} \mathrm{(a)} \mathrm{and} 12 \mathrm{~h} \mathrm{(b)}$ at $700^{\circ} \mathrm{C}$, measured at $6 \mathrm{~K}$. 

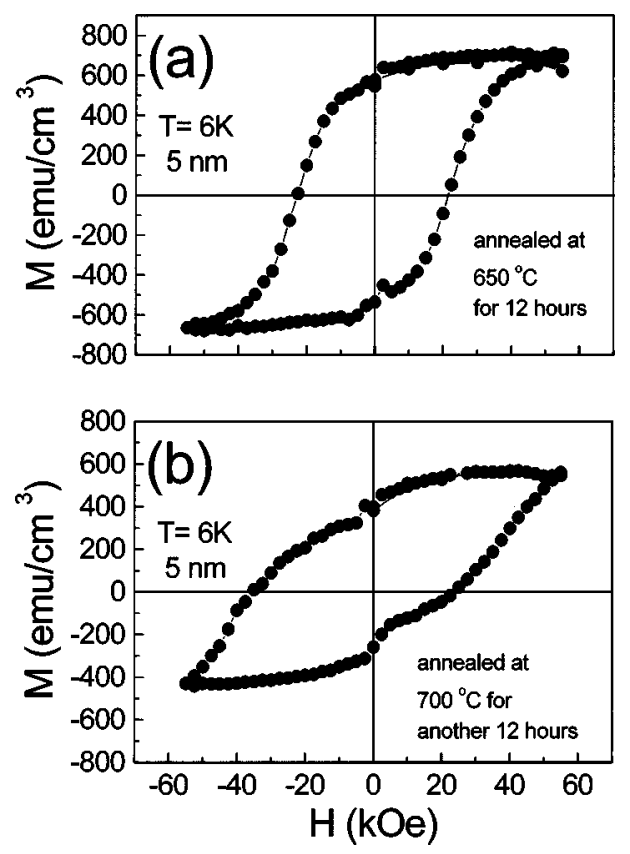

FIG. 5. Hysteresis loops of a $5 \mathrm{~nm} \mathrm{CoPt} \mathrm{film} \mathrm{on} \mathrm{a} \mathrm{quartz} \mathrm{substrate} \mathrm{measured}$ at $6 \mathrm{~K}$. (a) The film was annealed at $650{ }^{\circ} \mathrm{C}$ for $12 \mathrm{~h}$. (b) The same film was annealed at $750{ }^{\circ} \mathrm{C}$ for another $12 \mathrm{~h}$.

actions between the crystallites. The magnetic interaction is likely to reduce the $H_{c}$ value. The coupling magnetic domains may have incoherent domain rotations.

In order to reduce the size of the crystallites in the film and study the effect of the ordering on the $H_{c}$ value, we compare 5-nm-thick samples that were annealed at $700{ }^{\circ} \mathrm{C}$ for 3 and $12 \mathrm{~h}$. Hysteresis loops of CoPt films measured at 6 $\mathrm{K}$ are shown in Fig. 4. An $H_{c}$ value of $25 \mathrm{kOe}$ and a saturation magnetization of $668 \mathrm{emu} / \mathrm{cm}^{3}$ were observed in the sample annealed at $700{ }^{\circ} \mathrm{C}$ for $3 \mathrm{~h}$. An $H_{c}$ value of $33 \mathrm{kOe}$ and a saturation magnetization of $586 \mathrm{emu} / \mathrm{cm}^{3}$ were observed in the sample annealed at $700{ }^{\circ} \mathrm{C}$ for $12 \mathrm{~h}$. The variation of the saturation magnetization may be due to the order and disorder of the CoPt phase in the sample. The saturation magnetization of the as-prepared film with a face-centeredcubic structure (Co and $\mathrm{Pt}$ atoms are disorderly distributed) are higher than those with the ordered CoPt fct phase. As shown in Fig. 4(a), the disorder phase with a has low $H_{c}$ value may cause the drop of the magnetization near zero applied magnetic field. We have noted that the hysteresis loop is not symmetrical (it is a minor loop). The variation of the saturation magnetization may be also due to the fact that the applied magnetic field (55 kOe) was not high enough to saturate this sample.

As shown in Fig. 5, this sample was first annealed at $650^{\circ} \mathrm{C}$ for $12 \mathrm{~h}$. It was observed with an $H_{c}$ of $23 \mathrm{kOe}$ and the saturation magnetization of $712 \mathrm{emu} / \mathrm{cm}^{3}$. Then it was annealed at $700^{\circ} \mathrm{C}$ for another $12 \mathrm{~h}$. The $H_{c}$ value was as high as $37 \mathrm{kOe}$. It is very clear that the hysteresis loop is not symmetrical. For a higher applied magnetic field, a larger $H_{c}$ value is expected. Through two-step annealing, the $H_{c}$ value was improved by about $4 \mathrm{kOe}$ as compared to one-step annealing. This may be due to the formation of smaller crystallites in the films at lower temperature and an ordered structure after annealing at $700{ }^{\circ} \mathrm{C}$ for $12 \mathrm{~h}$. However, the reason needs further research.

\section{SUMMARY}

We showed that CoPt thin films with well-separated crystallites and the well-ordered fct structure were achieved by controlling the annealing time and annealing temperature. As observed by MFM, noninteracting magnetic domains are important in achieving high $H_{c}$ values. We also studied twostep annealing. From the experimental results, we have enhanced the magnetic coercivity of a CoPt film to $37 \mathrm{kOe}$.

\section{ACKNOWLEDGMENT}

Research at the University of Nebraska was supported by the Army Research Office under Grant No. DAAG55-98$1-0014$

${ }^{1}$ K. Babcock, V. Elings, M. Dugas, and S. Loper, IEEE Trans. Magn. 30, 4503 (1994).

${ }^{2}$ S. H. Liou and Y. D. Yao, J. Magn. Magn. Mater. (to be published).

${ }^{3}$ D. Weller, H. Brandle, G. Gorman, C.-J. Lin, and H. Notarys, Appl. Phys. Lett. 61, 2726 (1992).

${ }^{4}$ Song. S. Xue, James. F. Dolejsi, and Patrik. J. Ryan, IEEE Trans. Magn. 34, 882 (1998).

${ }^{5}$ S. H. Liou, Y Liu, S. S. Malhotra, M. Yu, and D. J. Sellmyer, J. Appl. Phys. 79, 5060 (1996).

${ }^{6}$ E. S. Murdock, IEEE Trans. Magn. 28, 3078 (1992).

${ }^{7}$ M. R. Visokay and R. Sinclair, Appl. Phys. Lett. 66, 1692 (1995).

${ }^{8}$ B. D. Cullity, Introduction to Magnetic Materials (Addison Wesley, Menlo Park, CA, 1972).

${ }^{9}$ H. Kronmüller, Phys. Status Solidi. 144, 385 (1987). 